\title{
Collagenous colitis: Histologic progression, extraintestinal features and lack of response to 5-ASA - A case report
}

FRANZJOSEF SCHWEIGER, BSC, MD, FRCPC, FACG

ABSTRACT: Collagenous colitis is a clinicopathologic syndrome which presents as chronic, watery, nonbloody diarrhea. Colonic biopsies characteristically show a thick subepithelial collagen band. Barium enema and colonoscopy generally fail to establish the diagnosis. This case report provides evidence for histologic progression over time, pancolonic involvement and the presence of extraintestinal features of collagenous colitis. The reported patient showed no response to 5-aminosalicylic acid. Colonoscopic biopsies in cases of chronic diarrhea can save the patient repeated, uncomfortable and costly investigations. Can J Gastroenterol 1990;4(1):19-22

Key Words: 5-aminosalicylic acid, Collagenous colitis, Chronic diarrhea, Extraintestinal features

\section{La colite du collagène: Evolution histologique progressive,} manifestations extraintestinales et manque de réponse à 5-ASA

RESUME: La colite du collagène est un syndrome anatomoclinique caractérisé par une diarrhée chronique aqueuse non sanglante. De manière caractéristique, les biopsies coliques montrent une épaisse bride de collagène sous-épithéliale. Le lavement baryté et la côlonoscopie ne parviennent généralement pas à établir le diagnostic. Le cas présent montre une évolution histologique progressive, une atteinte pancolique et des manifestations extraintestinales propres à la colite du collagène. Le patient concerné n'a pas répondu à l'acide 5-aminosalicylique. Dans les cas de diarrhée chronique, le recours aux biopsies côlonoscopiques peut épargner au patient des investigations répétées, désagréables et coûteuses.

The Moncton Hospital, Moncton, New Brunswick

Correspondence and reprints: Dr F Schweiger, 100 Arden Street, Suite 405, Moncton, New Brunswick EIC 4B7. Telephone (506)858-8441

Received for publication June 23, 1988. Accepted November 13, 1989

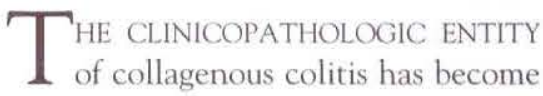
increasingly recognized since its first description 13 years ago (1), with at least 50 cases reported in the English literature.

A case of collagenous colitis is reported which not only demonstrates the difficulty in diagnosis but also adds information with respect to mucosal progression, possible extraintestinal manifestations and treatment of this condition.

\section{CASE PRESENTATION}

A 71 -year-old female presented with a 16 year history of intermittent diarrhea. The diarrhea was characterized by up to 15 loose to watery bowel movements per day, which often awakened her at night. It was preceded by bilateral lower abdominal cramps and associated with tenesmus. She denied the passage of blood but did notice mucus. These episodes occurred several times per year lasting up to three to four weeks and were followed by more regular soft to loose bowel movements num- 


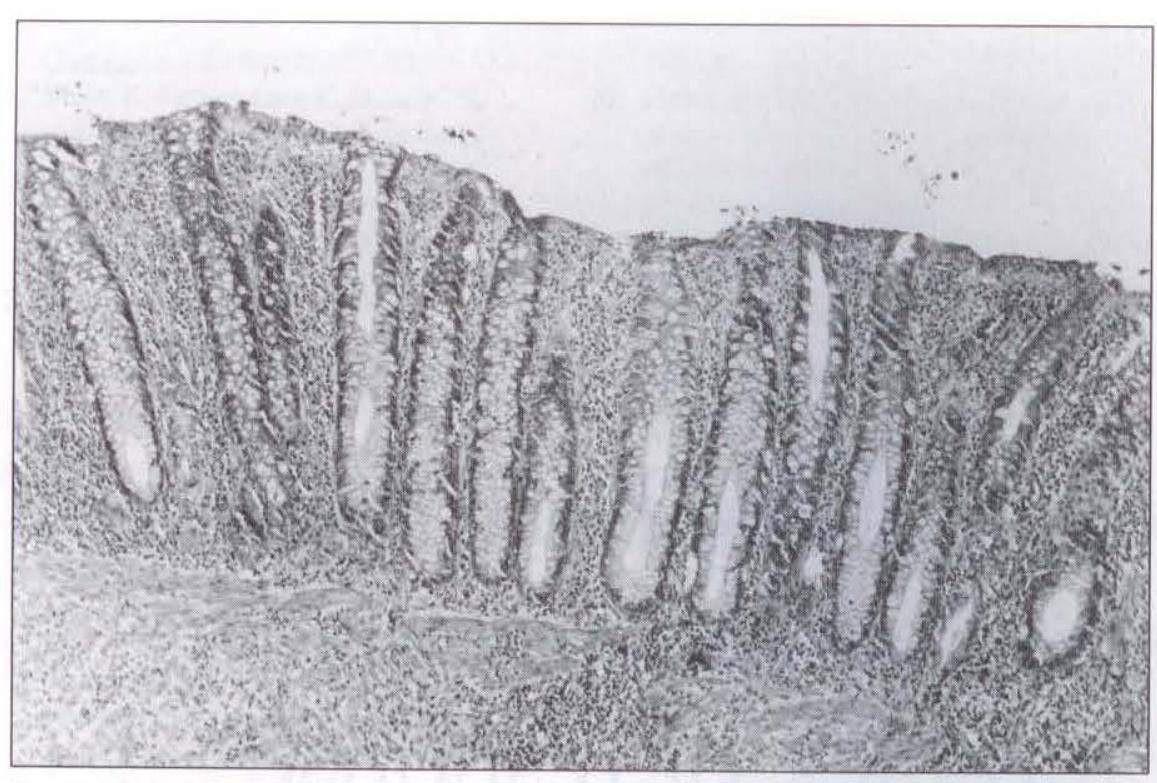

Figure 1) Rectal biopsy showing marked mononuclear inflammatory cell infiltration in the lamina propria with preservation of crypt architecture and normal goblet cells. (Hematoxylin and eosin $\mathrm{x}$ 300)

bering two to three per day. Over the past year prior to admission she began having more frequent bouts of diarrhea often leading to fecal incontinence. In addition, she complained of mild anorexia, nausea and severe heartburn that was relieved by $\mathrm{H}_{2}$ blocker therapy.

At age 56 she was found to have a slightly raised erythrocyte sedimentation rate, but stool cultures, sigmoidoscopy and barium $x$-rays of her upper and lower gastrointestinal tract were normal. An exploratory laparotomy revealed cholelithiasis and her gallblad- der was removed. A jejunal biopsy was reported as normal.

At age 64 she was readmitted because of worsening diarrhea. She was found to have seronegative deforming arthritis involving the small joints of her hands and knees. Stool cultures, sigmoidoscopy, barium enema and liverspleen scan were negative and she was treated with a fibre-enriched diet and psyllium hydrophilic mucilloid.

One year later she required readmission to hospital because of persistence of her symptoms despite the admini-

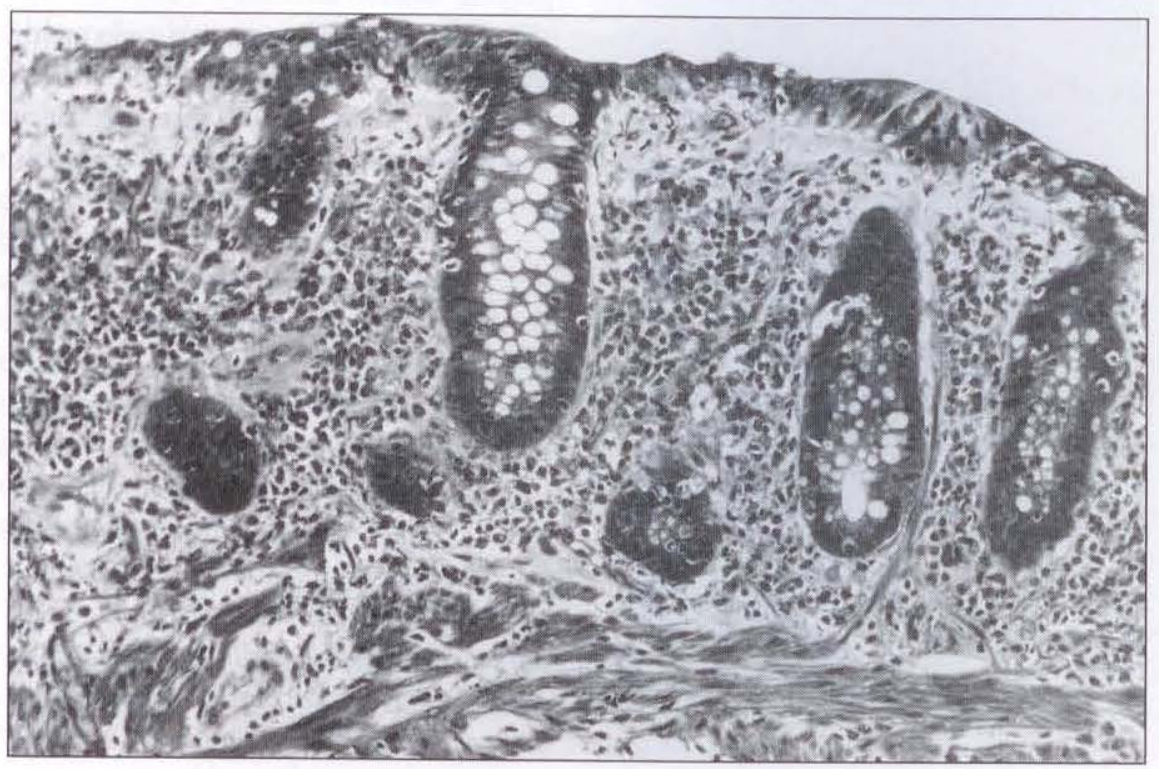

Figure 2) Biopsy of transwerse colon displaying marked subepithelial collagen deposition with marked increase of mononuclear inflammatory cells in the lamina propria. (Hematoxylin and eosin $\times 900$ ) stration of codeine and loperamide. Repeat barium studies, a D-xylose excretion test, Schilling test, serum gastrin levels and gastric analysis were all normal as was the serum cortisol and a 24 h urine sample for 5-hydroxy. indoleacetic acid (5-HIAA). A $72 \mathrm{~h}$ stool collection yielded an average of $165 \mathrm{~g}$ of feces with $1.8 \mathrm{~g}$ of fat per $24 \mathrm{~h}$. A colonoscopy and repeat small bowel biopsy were within normal limits.

Further investigations during the following year again revealed negative stool cultures as well as a negative test for Clostridium difficile cytotoxin. A small bowel aspirate and string test failed to recover Giardia lamblia cysts or trophozoites. A sigmoidoscopy was normal but a random rectal biopsy demonstrated 'nonspecific colitis' (Figure 1). She was treated with total parenteral nutrition for 11 days which led to improvement of her diarrhea and weight gain. She was discharged on $\mathrm{co}$. deine but experienced intermittent relapses of cramps and diarrhea over the next five years.

She presented again recently and was found to have a slightly elevated blood glucose level which was treated by diet. She complained of periodic depression particularly since her husband's death two years earlier. She denied the use of laxatives. Other past medical history included recurrent pneumonias over the past 15 years, a hysterectomy, bilateral ligation of varicose veins and a hemorrhoidectomy.

There was no family history of inflammatory bowel disease or other intestinal disorders.

On examination the patient appeared depressed. Her head and neck were normal and there was no thyromegaly. The chest and cardiovascular system examination were unremarkable apart from a grade II/VI systolic ejection murmur radiating to the base. There were two old scars on her abdomen, which was slightly distended and tympanitic. There was mild diffuse tenderness throughout her abdomen but no evidence of organomegaly or mass. Rectal examination was normal. She had joint deformities affecting her proximal and distal interphalangeal joints, wrists and knees, 
but no actively inflamed joints were found. She had several patches of vitiligo over her forearms.

Further investigations in hospital demonstrated a normal complete blood count and erythrocyte sedimentation rate. Serum electrolytes, calcium and proteins were normal but the fasting blood glucose and glycosylated hemoglobin were mildly elevated. A $72 \mathrm{~h}$ stool collection resulted in a stool weight of $225 \mathrm{~g}$ per $24 \mathrm{~h}$ and $14 \mathrm{~g}$ of fat per day while on a $100 \mathrm{~g}$ fat containing diet. Stool electrolytes were potassium $99 \mathrm{mmol} / \mathrm{L}$, sodium $61 \mathrm{mmol} / \mathrm{L}$, chloride $68 \mathrm{mmol} / \mathrm{L}$, with a stool osmolality of $468 \mathrm{mmol} / \mathrm{L}$. The $\mathrm{pH}$ was 8 and stool was negative for occult blood and reducing substances.

Upper endoscopy revealed grade II ulcerative esophagitis and esophageal biopsy was consistent with this. Small bowel biopsy was normal. A colonoscopic examination was unremarkable but multiple biopsies obtained at $10 \mathrm{~cm}$ intervals from cecum to rectum showed the presence of collagenous colitis in all specimens (Figure 2). The patient was started on 5-aminosalicylic acid (5ASA) $800 \mathrm{mg}$ tid), a high fibre diet and psyllium mucilloid. Although she improved initially her diarrhea recurred after three weeks while on the medication and repeat biopsies showed no histologic improvement.

Subsequent therapy with sulfasalazine and oral prednisone was poorly tolerated and did not lead to symptomatic improvement. Currently, she is being treated with steroid enemas and she passes three to five semiformed bowel movements per day.

\section{DISCUSSION}

Collagenous colitis was first described by Lindström in 1976 (1) and has been the subject of recent reviews $(2,3)$. This clinicopathologic syndrome characteristically presents as a chronic watery diarrhea and colonic mucosal biopsies reveal the presence of a linear subepithelial fibrous thickening and a chronic inflammatory infiltrate in the lamina propria. As in the patient described, radiologic and even colonoscopic findings may be entirely normal or nonspecifically abnormal and the diag- nosis is eventually made only by mucosal biopsy $(2,4)$.

The disease appears to be most common in middle-aged to elderly women. The diarrhea is often intermittent, nonbloody, and associated with abdominal cramps. It is frequently misdiagnosed as a manifestation of irritable bowel syndrome (5). However, the presence of nocturnal diarrhea, fecal incontinence and weight loss, should suggest an organic cause for diarrhea.

The patient in this case report suffered from a seronegative peripheral polyarthritis; its association with collagenous colitis has repeatedly been reported (6-8). In addition, the occurrence of glucose intolerance, thyroid disease and the finding of antinuclear antibodies in some patients with collagenous colitis has been cited as evidence for an autoimmune pathogenetic mechanism (9). The presence of vitiligo has not been described previously.

The reported patient initially had a rectal biopsy five years prior to the finding of a thickened subepithelial collagen table in the same anatomic location. This initial biopsy revealed an active colitis consistent with the recently recognized entity of microscopic colitis (10). Hence, this case adds further support to the hypothesis that collagenous colitis and microscopic colitis are but different aspects of the same condition $(9,11,12)$. The pathogenesis of the formation of the collagen band is not completely understood, but likely requires the presence of chronic subepithelial inflammation (13). In addition, the existence of a local abnormality of collagen synthesis has been postulated (2).

This case demonstrates the pancolonic distribution of collagenous colitis (3,14). Characteristically, jejunal biopsies are normal except in rare cases in which celiac disease was found to be associated with collagenous or microscopic colitis $(12,14-17)$. However, there was no evidence of small bowel villous atrophy in this patient and her mild steatorrhea remains unexplained.

The treatment response to various drugs is unpredictable and often disappointing (14). Both sulfasalazine and corticosteroids have induced remission in several cases $(2,9)$ but have been ineffective in others (14). Anecdotal therapeutic success has been achieved with a number of other compounds including mepacrine (13), metronidazole (18), and bismuth subsalicylate (19). Sulfasalazine has been shown in several cases to lead not only to clinical but also histologic improvement seen in subsequent biopsies $(9,12)$. Whether this effect was brought about by the antimicrobial (sulfonamide) or anti-inflammatory (5-ASA) moiety, however, is not clear. This patient was treated with 5-ASA and despite a good therapeutic dose and duration of therapy there was no clinical or histologic response. Furthermore, sulfasalazine did not lead to improvement of diarrhea. Rams et al (2) proposed that collagenous colitis is an inflammatory disorder, possibly of infectious origin, which is initially characterized by an acute inflammatory process which progresses over time and results in a gradual increase of collagen which may act as a diffusion barrier, further contributing to diarrhea. Conceivably, neither anti-inflammatory nor antimicrobial agents are effective at this later stage of the disease.

Finally, this case report underlines the importance of colonic biopsies even in the absence of colonic findings in patients with unexplained chronic diarrhea. If positive, the diagnosis is established, and repeated, uncomfortable and costly investigations can be avoided.

ACKNOWLEDGEMENTS: The author acknowledges the help of Dr DA Malatjalian and Dr W Ying with the preparation of the photomicrographs.

\section{REFERENCES}

1. Lindström CG. 'Collagenous colitis' with watery diarrhea - A new entity? Pathol Eur 1976;11:87-9.

2. Rams H, Rogers AI, Ghandur-Mnaymneh L. Collagenous colitis. Ann Intern Med 1987;106:108-13.

3. Coverlizza S, Ferrari A, Scevola F, et al. Clinico-pathological features of collagenous colitis: Case report and literature review. Am J Gastroenterol 1986;81:1098-103. 
4. Salt WB II, Llaneza PP. Collagenous colitis: A cause of chronic diarrhea diagnosed only by biopsy of normal appearing colonic mucosa. Gastrointest Endosc 1986;32:421-3.

5. Giardiello FM, Bayless TM, Jessurun J, Hamilton SR, Yardley JH. Collagenous colitis: Physiologic and histopathologic studies in seven patients. Ann Intern Med 1987;106:46-9.

6. Erlendsson J, Fenger C, Meinicke J. Arthritis and collagenous colitis: Report of a case with concomitant chronic polyarthritis and collagenous colitis. Scand J Rheumatol 1983;12:93-5.

7. Farah DA, Mills PR, Lee FD, McLay A, Russell RI. Collagenous colitis: Possible response to sulfasalazine and local steroid therapy. Gastroenterology 1985;88:792-7.

8. Wiener MD. Collagenous colitis and pulmonary fibrosis. Manifestations of a single disease? J Clin Gastroenterol
1986;8:677-80.

9. Jessurun J, Yardley JH, Giardiello FM, Hamilton SR, Bayless TM. Chronic colitis with thickening of the subepithelial collagen layer (collagenous colitis): Histopathologic findings in 15 patients. Hum Pathol 1987;18:839-48.

10. Bo-Linn GW, Vendrell DD, Lee E, Fordtran JS. An evaluation of the significance of microscopic colitis in patients with chronic diarrhea. J Clin lnvest 1985;75:1559-69.

11. Teglbjaerg PS, Thaysen EH, Jensen $\mathrm{HH}$. Development of collagenous colitis in sequential biopsy specimens. Gastroenterology 1984;87:703-9.

12. Sylwestrowicz T, Kelly JK, Hwang WS, Shaffer EA. Collagenous colitis and microscopic colitis: The watery diarrhea-colitis syndrome. Am J Gastroenterol 1989;84:763-8.

13. Pieterse AS, Hecker R, Rowland R. Collagenous colitis: $A$ distinctive and potentially reversible disorder. J Clin Pathol 1982;35:338-40.

14. Kingham JGC, Levison DA, Morson $\mathrm{BC}$, Dawson AM. Collagenous colitis. Gut 1986;27:570-7.

15. Hwang WS, Kelly JK, Shaffer EA, Hershfield NB. Collagenous colitis: A disease of pericryptal fibroblast sheath? J Pathol 1986;149:33-40.

16. Hamilton I, Sanders S, Hopwood D, Bouchier IAD. Collagenous colitis associated with small intestinal villous atrophy. Gut 1986;27:1394-8.

17. Breen EG, Coughlan G, Connolly CE, Stevens FM, McCarthy CF. Coeliac proctitis. Scand J Gastroenterol 1987;22:471-7.

18. Mogensen AM, Olsen JH, GudmandHoyer E. Collagenous colitis. Acta Med Scand 1984;216:535-40.

19. Girard DE, Keeffe EB. Therapy for collagenous colitis. Ann Intern Med 1987;106:909. 


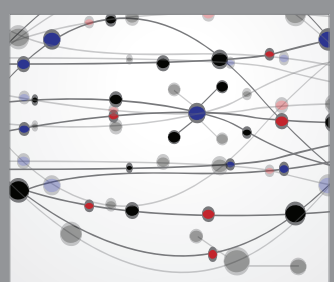

The Scientific World Journal
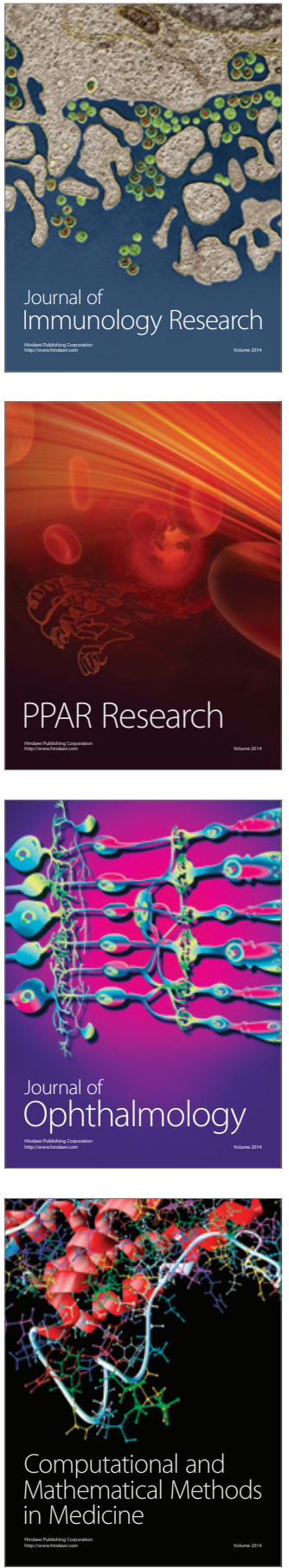

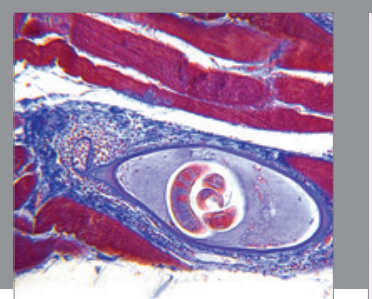

Gastroenterology Research and Practice

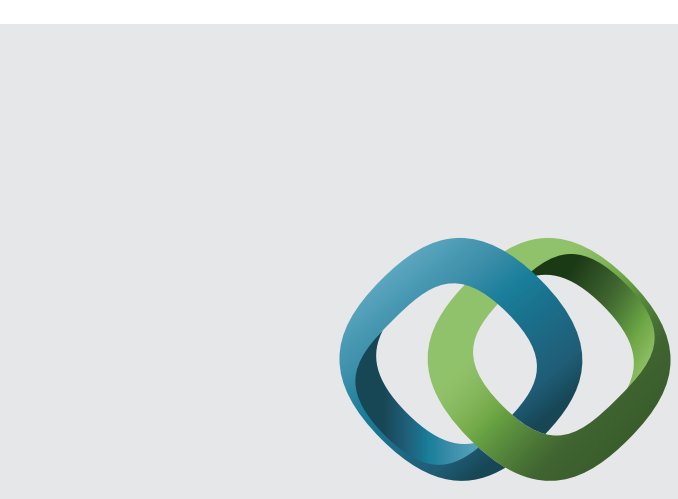

\section{Hindawi}

Submit your manuscripts at

http://www.hindawi.com
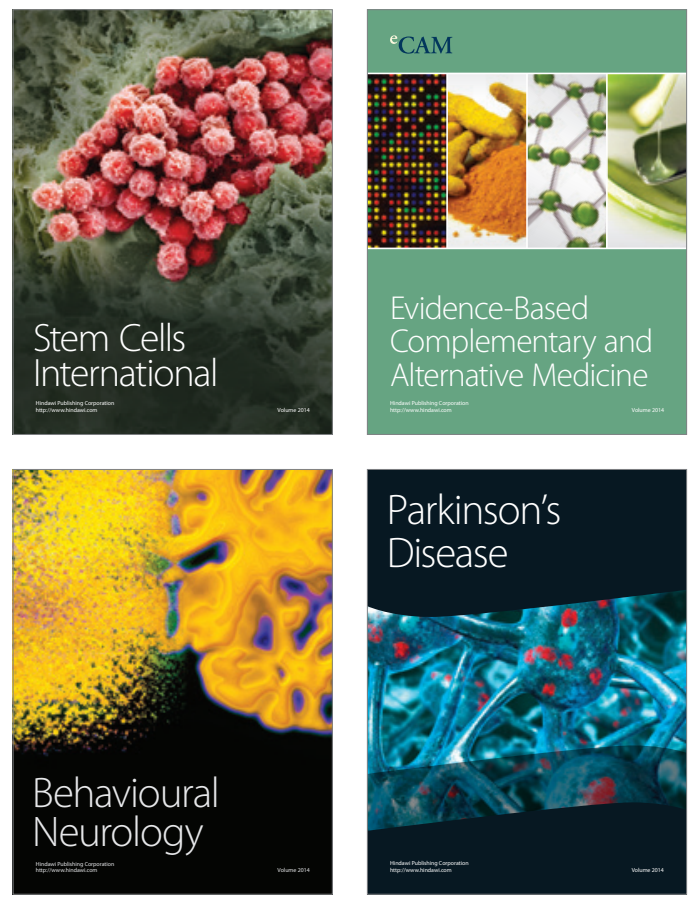
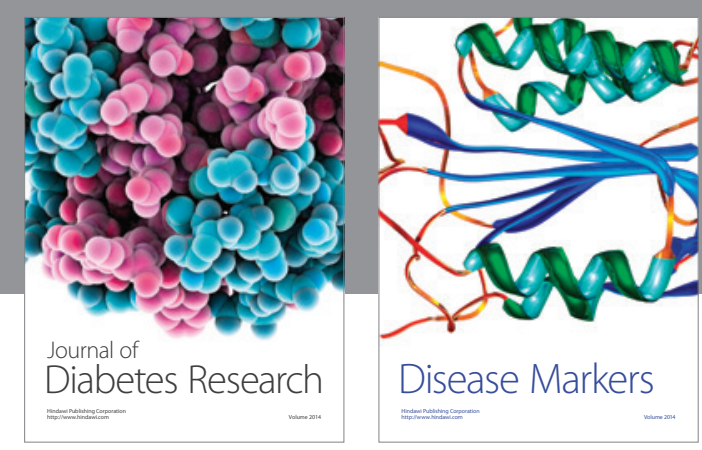

Disease Markers
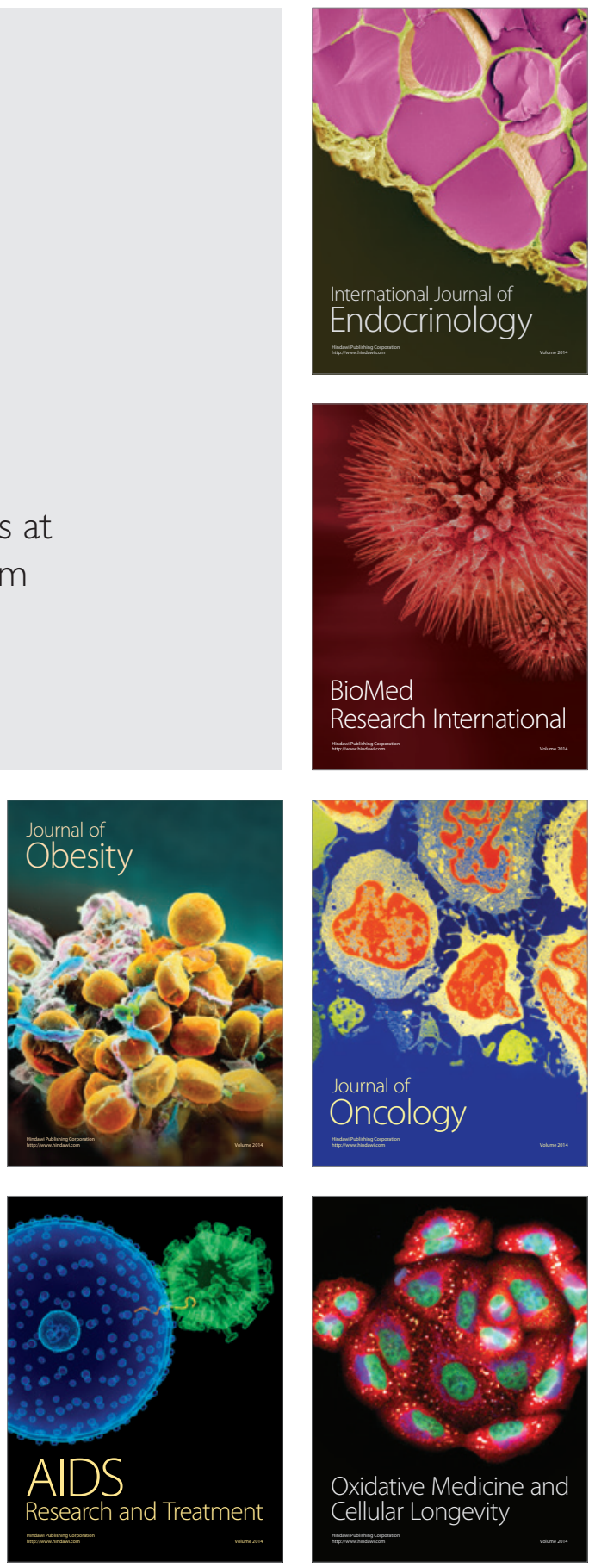